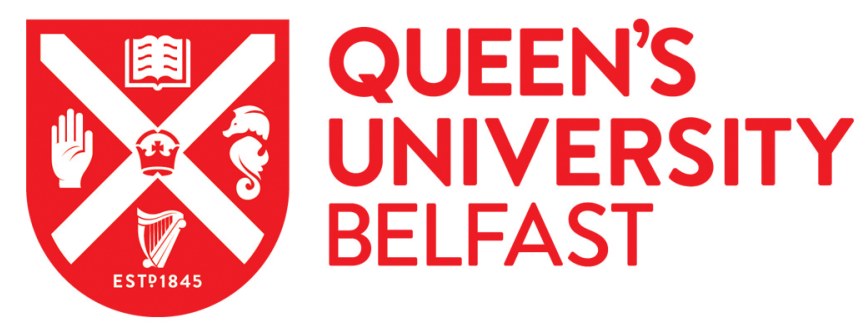

\title{
"A tool doesn't add anything": The importance of added value: use of observational pain tools with patients with advanced dementia approaching the end of life - a qualitative study of physician and nurse experiences and perspectives
}

De Witt Jansen, B., Brazil, K., Passmore, P., Buchanan, H., Maxwell, D., Mcllfatrick, S., Morgan, S., Watson, M., \& Parsons, C. (2018). "A tool doesn't add anything": The importance of added value: use of observational pain tools with patients with advanced dementia approaching the end of life - a qualitative study of physician and nurse experiences and perspectives. International Journal of Geriatric Psychiatry, 33(10), 1346-1354. https://doi.org/10.1002/gps.4931

Published in:

International Journal of Geriatric Psychiatry

Document Version:

Peer reviewed version

Queen's University Belfast - Research Portal:

Link to publication record in Queen's University Belfast Research Portal

Publisher rights

(C) 2018 John Wiley \& Sons, Ltd.

This work is made available online in accordance with the publisher's policies. Please refer to any applicable terms of use of the publisher.

\section{General rights}

Copyright for the publications made accessible via the Queen's University Belfast Research Portal is retained by the author(s) and / or other copyright owners and it is a condition of accessing these publications that users recognise and abide by the legal requirements associated with these rights.

Take down policy

The Research Portal is Queen's institutional repository that provides access to Queen's research output. Every effort has been made to ensure that content in the Research Portal does not infringe any person's rights, or applicable UK laws. If you discover content in the

Research Portal that you believe breaches copyright or violates any law, please contact openaccess@qub.ac.uk. 
"A tool doesn't add anything". The importance of added value: use of observational pain tools with patients with advanced dementia approaching the end of life - a qualitative

5 Running title: Pain assessment in advanced dementia

6

7 Bannin De Witt Jansen LLB, BSc, MA, PhD. School of Pharmacy, Queen's University Belfast, 8 Belfast, United Kingdom*

9

10 Kevin Brazil BSc, PhD. School of Nursing and Midwifery, Belfast, United Kingdom.

11

12 Peter Passmore BSc, MB BCh BAO, MRCP, MD, FRCP (London), FRCP (Glasgow), FRCPI.

13 Centre for Public Health, School of Medicine, Dentistry and Biomedical Sciences, Belfast, 14 United Kingdom.

15

16 Hilary Buchanan $\mathrm{MB}$ BCh BAO, DRCOG, MRCGP. Patient and Public Involvement 17 Representative, Carer for a person living with dementia, Belfast, United Kingdom

18

Doreen Maxwell MB BCh BAO, DRCOG, MRCGP. Kerrsland Surgery, Belfast, United 20 Kingdom.

*NHS Tayside, Tayside Medical Science Centre, Ninewells Hospital \& Medical School, Residency Block, Level 3, George Pirie Way, Dundee, Scotland.

**Hospice UK, 34-44 Britannia Street, London, UK, WC1X 9JG. 
22 Sonja McIlfatrick BSc, MSc, PhD, RGN, RNT. Institute of Nursing and Health Research,

23 Ulster University, Jordanstown, United Kingdom.

24

25 Sharon M. Morgan MB BCh BAO, DRCOG, MRCGP. Marie Curie Hospice, Belfast, United 26 Kingdom.

27

28

Max Watson BD, MB BCh BAO, M Phil, MSc, MRCGP, DRCOG, DCH, DMH. Northern

Ireland Hospice, Belfast, United Kingdom**

30

Carole Parsons PhD, MPharm, MPSNI. School of Pharmacy, 97 Lisburn Road, Belfast,

Queen’s University Belfast, BT9 7BL, United Kingdom. Email: c.parsons@qub.ac.uk;

Telephone: +44 (0) 289097 2304; Fax: +44 (0) 289024 7794. Corresponding author

34

35

36

37

38

39

40

41

42

43

*NHS Tayside, Tayside Medical Science Centre, Ninewells Hospital \& Medical School, Residency Block, Level 3, George Pirie Way, Dundee, Scotland.

**Hospice UK, 34-44 Britannia Street, London, UK, WC1X 9JG. 
Word count: 3204

45

46

\section{Acknowledgments}

47 The authors would like to thank all research participants, participating hospices and the local collaborators within the HSC Trusts who facilitated and supported this study.

\section{Funding}

This research was funded by HSC Research \& Development Division (HSC R\&D), Public Health Agency, Northern Ireland, in association with the Atlantic Philanthropies (Reference: $\mathrm{COM} / 4885 / 13)$.

54

\section{Abstract}

56 Background: Observational Pain Tools (OPTs) are widely recommended in healthcare

57 policies, clinical guidelines and recommendations for pain assessment and management.

58 However, it is unclear whether and how these tools are used for patients with advanced dementia approaching the end of life. Aim: To explore hospice, secondary and primary care physicians' and nurses' use of OPTs with patients dying with advanced dementia and their perspectives on practice development and training needs. Methods: Twenty-three physicians and 24 nurses with experience of caring for people dying with advanced dementia were recruited from primary care surgeries $(n=5)$, hospitals $(n=6)$, hospices $(n=4)$ and nursing homes

$64(\mathrm{n}=10)$. Semi-structured, face-to-face interviews were conducted. Interviews were digitally recorded, transcribed verbatim and thematic analysis applied to identify core themes. Results: Three key themes emerged: (1) use of OPTs in this vulnerable patient population; (2) barriers

67 to the use of OPTs and lack of perceived 'added value' and (3) perspectives on practice 
68 development and training in pain assessment in advanced dementia at end of life. Just over one-quarter of participants $(\mathrm{n}=13)$ routinely used OPTs. Reasons for non-use included perceived limitations of such tools, difficulties with their use and integration with existing

71 practice and lack of perceived 'added value'. Most participants strongly emphasised a need for 72 ongoing training and development which facilitated transfer of knowledge and 73 multidisciplinary skills across professions and specialties. Conclusions: Health professionals 74 require ongoing support in developing and integrating change to existing pain assessment 75 protocols and approaches. These findings have important implications for health education, 76 practice and policy.

77250 words

78

79 Keywords: Dementia; Pain; Pain Measurement; Pain Assessment; Palliative Care; Education, Medical; Nursing; Physicians; Nurses

81

82

\section{Key-points}

83

- Barriers to implementing and integrating use of standardised observational pain tools for people dying with advanced dementia include difficulties experienced with using the tools themselves, uncertainty arising from the limitations of tools and perceived lack of value in

87 using them.

- Lack of guidance in health policies and recommendations as to how these tools might be effectively integrated with existing approaches resulted in lack of adoption of recommendations and strengthened commitment to existing practice. 
- Healthcare professionals emphasised a need for increased investment in ongoing, needsdriven, clinician-led training and development in pain assessment and management in dementia.

\section{Introduction}

Pain is common in people with advanced dementia approaching end of life, causing significant concern for healthcare professionals (HCPs) responsible for its assessment and management. ${ }^{1-}$

${ }^{3}$ Untreated pain has serious implications for quality of life and is associated with onset or exacerbation of depression, delirium, sleep disturbance, cognitive decline and 'sundown syndrome' (neuropsychiatric symptoms including confusion, aggression or anxiety in the afternoon, evening and at night). ${ }^{4,5}$ Increasing evidence supports an association between pain and behavioural and psychological symptoms of dementia. ${ }^{6-9}$ Pain assessment and management form cornerstones of palliative care for people dying with dementia but are challenging for patients unable to reliably self-report due to cognitive deterioration. ${ }^{1-3}$ Previous studies have reported under-recognition and potentially inappropriate treatment of pain among people with dementia particularly in nursing home settings. ${ }^{10-13}$

Increasing research focus on pain assessment in dementia has led to the development of numerous observational pain tools (OPTs), which require observation of patients for several behavioural and nonverbal indicators of pain and calculation of an aggregated score to indicate estimated pain intensity (mild, moderate, severe). ${ }^{14,15}$ Although use of OPTs is supported as part of best practice care for people living and dying with dementia, there is ongoing debate regarding their validity, reliability and clinical utility in practice. ${ }^{15-21}$ Much of this stems from wide variation in methods, participants, disease severity and settings in which these tools were 
117 developed, and the paucity of studies which have robustly and systematically trialled, evaluated

118 and reported on their impact on patient outcomes. ${ }^{15}$ Additionally, many of the behavioural and

119 nonverbal cues that indicate pain also present in expressions of non-pain related distress; there

120 is no clear indication in the research literature as to whether OPTs are able to distinguish

121 between pain and distress or whether they may detect both. ${ }^{22-24}$ HCPs experience several

122 challenges with use of OPTs in practice. These include differentiating pain from distress,

123 insufficient training and support for conducting pain assessments with severely cognitively

124 impaired patients unable to self-report, misguided perceptions regarding pain experiences and

125 neural processing in people with dementia, and workload and other organisational/institutional

126 pressures which restrict time available to conduct and interpret pain assessments. ${ }^{6,25-30}$

127

128 Despite these challenges, health policies, clinical recommendations and guidelines widely

129 recommend use of OPTs when assessing pain in people with dementia and many private health

130 providers mandate their use as part of pain assessment protocols. ${ }^{16-18}$ However, exploration of

131 whether, to what extent and how HCPs integrate and apply these tools in clinical practice is

132 lacking in the current literature.

133

134 This study aimed to explore hospice, secondary and primary care physicians' and nurses' use

135 of OPTs with patients dying with advanced dementia and their perspectives on practice

136 development and training needs in this area.

138 Methods

139 Sample and setting

140 Criterion purposive sampling was used to recruit a maximum variation sample of physicians

$141(n=23)$ and nurses $(n=24)$ from general practice surgeries $(n=5)$, hospitals $(n=6)$, hospices $(n=4)$ 
142 and nursing homes $(\mathrm{n}=10)$. The following inclusion criterion was applied: experience of caring

143 for people in the advanced stages of dementia who were approaching the end of life or who

144 had since died. Participants were recruited from care settings geographically dispersed across

145 a region of the United Kingdom (Northern Ireland [NI]).

147 Recruitment

148 Index contacts (Hospice Medical Directors [ $n=4]$, secondary care consultant physicians [n=4],

149 General Practitioners [GPs; $n=7]$ and nursing home managers $[\mathrm{n}=16]$ ) with experience caring 150 for people with advanced dementia approaching the end of life disseminated study information

151 to eligible staff and identified other suitable organisations to approach for participation. Study

152 information included a cover letter (outlining aims and objectives and inviting participation), 153 participant information sheet, contact consent form and a return-address, postage paid 154 envelope. All individuals who returned a contact consent form were contacted by the research 155 fellow (BDWJ) by telephone and provided with a verbal summary of study aims and objectives. 156 Interviews were arranged for those interested in participation. Recruitment ceased when no 157 further novel data were identified and data saturation was achieved.

\section{Data collection and analysis}

160 Data were collected via semi-structured, face-to-face interviews conducted in participants' 161 place of work between June 2014 and September 2015. An interview guide was used (Table

162 1); questions were derived from literature review, consideration of gaps in current knowledge, and the study aims and objectives. These were refined through an iterative process of

164 discussion with the Project Management Group (PMG) comprising clinicians in geriatrics/dementia and palliative care, academics specialising in palliative care, nursing and

166 pharmacy, General Practitioners (GPs) with a special interest in older adults, dementia and 
palliative care, and one patient and public involvement representative. Prior to interview, participants were provided with a verbal summary of the project aims, a statement regarding data protection and participant anonymity, and an opportunity to ask questions or raise concerns. Participants provided written informed consent.

172 Interviews were conducted, digitally audio-recorded and transcribed verbatim by BDWJ, a

173 female postdoctoral researcher with training and previous experience in qualitative research methods as part of her postgraduate studies. Participants were aware that the researcher was undertaking this study as part of a funded programme of work in the School of Pharmacy,

176 Queen's University Belfast, and some participants had knowledge of BDWJ due to her 177 previous postgraduate research activities.

178

179 A selection of transcripts were checked for accuracy against digital recordings by KB and HB. 180 Thematic analysis, using Braun and Clarke's (1996) paradigm, was applied to identify core 181 themes, and NVivo 10.0 software (QSR International [UK] Ltd, Cheshire, UK) facilitated 182 storage and organisation of data during analysis. ${ }^{31}$ BDWJ completed analysis of the full data set; a selection of data was also independently analysed by $\mathrm{KB}$ and $\mathrm{CP}$ and compared with this analysis. Core themes were then discussed and agreed.

Ethics and governance

187 Ethical approval was granted by the Office for Research Ethics Committees Northern Ireland 188 (ORECNI) [(14/NI/0013)]. Health and Social Care Trust governance permissions were granted and the research protocol and supporting documentation were reviewed and approved by participating hospice ethics committees. 


\section{Results}

194 Forty-seven HCPs (23 physicians and 24 nurses) participated in the study. Physicians' average 195 length of clinical experience was 17.5 years (range: 5 years to 31 years); nurses had on average 19613.8 years of clinical experience (range: 3 months to 34 years). A full profile of participant characteristics is available in Table 2. Average interview duration was 18 minutes for physicians and 37.9 minutes for nurses.

199

200 Key themes

201 Three core themes were identified: (1) use of OPTs in advanced dementia towards the end of life; (2) barriers to the use of OPTs and the importance of 'added value' and (3) perspectives on practice development and training in pain assessment in advanced dementia in end of life care.

Use of OPTs in advanced dementia towards the end of life

207 Pain assessment protocols in all care settings from which participants were recruited mandated or recommended use of OPTs for people with dementia (at all stages). However, only 13 (27.6\%) participants (nurses $n=11$; physicians $n=2$ ) used these tools with patients in advanced stages approaching the end of life. The most commonly used tool was the Abbey Pain Scale

211 (36) $(\mathrm{n}=12 ; 92 \%)$; one participant used an in-house purpose-designed pain assessment

212 protocol. Within this group, attitudes varied regarding use and efficacy of these tools. Five participants (two hospice nurses, two nursing home nurses and one secondary care physician) reported that appropriate use, in accordance with instructions and as part of wider pain protocols, resulted in more prompt recognition of pain, revealed patients' patterns of presenting 
pain, provided estimation of pain severity, facilitated monitoring of treatment response and

217 enabled continuity of pain assessment and management across changing staff shifts (Table 3).

218 Use of OPTs facilitated pain reporting and communication within and across teams and 219 specialties; secondary care participants believed that pain scores, as clinical measures, were 220 more universally understood across specialties than qualitative descriptions (Table 3). Nursing home nurses believed that standardised assessments improved pain reporting to GPs and reported that OPTs were useful in helping less experienced staff recognise pain (Table 3).

Most participants in this group $(n=8)$ reported using OPTs to comply with care provider or local trust protocols, but questioned their efficacy and reliability for patients dying with advanced dementia. Many believed that the OPT mandated or recommended for use (in these cases, the Abbey Pain $\mathrm{Scale}^{32}$ ) did not seem appropriate for use for these patients. Most reported difficulty observing behavioural and nonverbal cues in patients with flat affect, those who fluctuated in consciousness and those exhibiting conservative responses to pain. Uncertainty as to whether behavioural and nonverbal cues observed were pain-related or indicators of non-pain related distress or behavioural and psychological symptoms of dementia was widely reported (Table 3). Most expressed a belief that pain scores lacked clinical meaning in the absence of other contextual and collateral knowledge about the patient. All eight participants reported that they did not document pain scores nor were they considered in treatment decisions (Table 3).

Barriers to the use of OPTs and the importance of 'added value' Most participants ( $\mathrm{n}=34 ; 72 \%$ ), of which physicians formed the majority ( $\mathrm{n}=21 ; 61.76 \%$ ), did not use OPTs with patients dying with advanced dementia. Beliefs and perceptions regarding

240 the limitations of such tools, in addition to difficulties implementing and integrating their 
application with existing practices motivated decisions to forgo their use. Most participants expressed strong beliefs that OPTs did not add anything of value to existing approaches (Table

243 3). Drawing from a holistic evidence base which included: patients' medical and histories;

244 recent and current symptoms; collateral psychosocial history from key care staff, allied 245 professionals and patients' families; and clinical and physical examinations; was perceived to 246 be a more thorough approach to assessment. For many, a relatively simplistic tool was not 247 considered a suitable substitute for clinical training and experience (Table 3).

In many cases, OPTs had dropped out of use due to inconsistent use and documentation of tools, wide variation in pain scores for the same patient depending on which member of staff conducted the assessment, and tension among staff regarding pain scoring and interpretation. In some cases, experienced professionals had withdrawn their use due to staff completing assessment paperwork in the absence of patient observation and review (Table 3). Use of a simple tool in a clinical area widely recognised as complex was perceived to disregard HCPs' years of extensive training and experience and was widely criticised (Table 3). These participants also commented on the lack of sound rationale regarding the selection of a tool, information regarding the positive outcomes arising from its use and guidance regarding how the tool might be integrated with existing clinical practice and protocols (Table 3).

A need for considered translation of interventions from academic research to clinical practice which clearly describes a process of integration and demonstrates how such interventions improve current practice and/or patient outcomes was emphasised (Table 3). in end of life care 
266 Most participants reported that pain recognition and diagnosis of pain type, location and

267 intensity were challenging in this patient population, making appropriate pain management

268 difficult to achieve. Most emphasised a critical need for investment in upskilling HCPs across

269 settings and specialities to appropriately and confidently manage end of life care including pain

270 and symptom management (Table 3). Ongoing training and professional development in symptom assessment and management and end of life care was deemed essential. Most participants strongly emphasised that such training must be needs-driven, offer a balance of didactic training and patient case discussion, be focused on transferable knowledge and skills rather than theory, and be clinician-led and delivered (Table 3). Experienced physicians emphasised the need for robust evaluation of all training and educational interventions to determine their feasibility, utility, ability to deliver educational objectives and impact on staff and patient outcomes (Table 3).

\section{Discussion}

280 Main findings/results of the study

281 Although all participants in the present study appeared to be aware of health policy and recommendations regarding use of OPTs with patients with dementia, only a minority were routinely adopting this practice with patients dying with advanced dementia. Among these

284 individuals, there was variation in attitudes towards OPTs. A small minority had effectively integrated standardised OPT use with existing practice, resulting in positive outcomes including quicker recognition and understanding of pain experiences for newly admitted patients, improved continuity of pain assessment and management across staff and changing shifts, and improved pain reporting within and across care teams, professions, care settings and specialties. Other studies have reported similar positive outcomes including improvements in 
symptom assessment and management and overall care provision. ${ }^{33}$ However, many participants who reported using OPTs did so solely to comply with local recommendations or healthcare policies, did not use the scores from these tools to inform treatment decisions and in many cases, did not document scores. Doubts regarding the clinical utility of scores from subjective observation as measures of pain (rather than distress or both pain and distress), and difficulties using tools with patients unable or unaccustomed to express behavioural and nonverbal signs of pain, resulted in uncertainty regarding OPT use. In these cases, participants abandoned pain scores, relying instead on existing practices and protocols to inform treatment decisions. Other studies have reported similar challenges experienced by HCPs using OPTs with people with dementia. ${ }^{25-28}$

Most participants in this study did not use OPTs when assessing pain in people with advanced dementia in the final month of life. Beliefs about the limitations of OPTs, difficulties experienced in their application with dying patients, inconsistencies in their use and documentation, staff disagreement regarding observational scores, and beliefs that the outcomes of such assessment did not offer anything of 'added value', were key reasons for non-use. Participants' narratives revealed largely consistent approaches to pain assessment in which contextual knowledge of the patient was drawn from multiple sources including medical and pain histories (pain threshold, response to pain, pain coping strategies), current and recent symptoms, clinical examinations, medication regimens, direct patient contact and knowledge of psychosocial history provided by care staff, patients' families and significant others (e.g. clergy). This approach largely follows published practice guidelines for assessing pain in older

312 adults with dementia. ${ }^{34}$ However, evidence has suggested that overreliance on personal

313 knowledge and collateral information alone may also prove an inadequate approach to pain 314 assessment if attitudes towards the patient population are negative, the patient is unknown or 
unfamiliar to the care team or staff are inexperienced in recognising the behavioural indicators

316 of pain in people dying with dementia. ${ }^{35-37}$ Other studies have identified a need for nursing

317 home staff to receive ongoing, regular training and support in developing pain assessment

318 protocols, conducting pain assessments and responding appropriately to the outcome. ${ }^{38-40}$

320 Participants believed that health policy and other clinical directives were misdirected in 321 focusing on simple tools in a clinical area widely recognised as challenging and highly 322 complex. Failure to highlight the benefits of using OPTs and lack of guidance on how they 323 might be integrated with existing practice were other criticisms raised. This finding, although 324 arising from small proportion of participants, echoes broader key themes reported in an increasing body of work examining effective translation of research interventions into clinical practice. ${ }^{41-46}$ This work has noted significant disparity between funding for healthcare research and the number of interventions subsequently successfully integrated and implemented in practice. ${ }^{41-46}$ It has been suggested that successful integration and implementation requires policies, directives, recommendations and other literature to reflect the values, culture, training and expertise of the professionals expected to adopt a novel intervention/approach. ${ }^{47,48} \mathrm{~A}$ focus on simplicity and the lack of knowledge and skills required to use the intervention may prove counterintuitive, resulting in rejection by HCPs, particularly physicians, who pride themselves on their professional knowledge, training and skills. ${ }^{46-48}$

Most participants emphasised a need for ongoing professional development and training in symptom management and end of life care provision in dementia, indicating a needs-driven, clinician-led approach which balanced didactic training with group discussion, skills transfer and patient case discussion. Such a model, known as Project ECHO $^{\odot}$ (Extension for Community Healthcare Outcomes), has been extensively trialled and evaluated across a range 
340 of health conditions internationally. ${ }^{49-59}$ This approach, which connects a multidisciplinary

341 expert panel within specific health conditions (e.g. dementia, diabetes etc.) with HCPs from

342 multiple specialties and professions across primary, secondary, hospice and community care

343 in real time clinics using teleconferencing technology, provides a forum for mentoring and

344 skills and knowledge transfer. Previous studies have demonstrated positive outcomes of Project

$345 \mathrm{ECHO}^{\odot}$ in increasing health professionals' knowledge, self-confidence and efficacy in

346 managing complex patients, improvements in patient outcomes and better integration of

347 primary and secondary care services, ${ }^{49-59}$ and recent work confirms the potential of Project

$348 \mathrm{ECHO}^{\odot}$ to support the delivery of high-quality care in pain assessment and management in

349 advanced and end stage dementia. ${ }^{60}$ Alternative approaches which take into account many

350 health professionals' views that OPTs disregard their clinical experience and over-simplify a

351 complex clinical picture by utilising them as part of a complex intervention may also enhance

352 pain assessment and management in this vulnerable patient population. ${ }^{33,61,62}$ To date, studies

353 have employed the discomfort scale Discomfort-Dementia of the Alzheimer's Type

354 (DisDAT), ${ }^{61,63}$ and the OPT Pain Assessment Checklist for Seniors with Limited Ability to

355 Communicate (PACSLAC) ${ }^{33,64}$ A recent clinical review of palliative care in patients with

356 dementia, which considered pain assessments and pain and behaviour interventions in addition

357 to tools for advanced care planning and clinical concerns in patients with dementia,

358 acknowledged the challenges in treating people with advanced dementia nearing the end of

359 life, and emphasised that adequate pain assessment and pharmacologic interventions and

360 nonpharmacological pain and behaviour interventions have an important role to play in

361 relieving suffering for these patients and their families and improving quality of life.

362

363

Limitations of the study 
The findings presented here must be interpreted with caution considering the self-selecting sample of participants which is likely to have drawn those with an interest in research and who are open to discussing their frank opinions and perspectives. Participants were recruited through index contacts, many of whom are research active; therefore, it is possible that this sample of participants leans towards examples of best practice. The self-selecting nature of recruitment has also drawn a concentration of professionals from general practice, hospice, palliative and nursing home care; further exploration of community care and other specialties in acute care is recommended as practices in these areas may vary.

\section{What this study adds}

This study revealed several key issues regarding integration and implementation of OPTs as part of pain assessment protocols in primary, secondary, hospice and nursing home settings.

Difficulties in applying the tools in practice, lack of guidance regarding the rationale for changing practice and how to integrate tools with existing protocols, along with uncertainty regarding clinical validity and reliability of these tools with dying patients with advanced dementia, were significant barriers to their use. Policy makers should exercise caution in placing emphasis on ease and simplicity of OPT use alone, particularly in clinically challenging and complex areas as this could prove counterintuitive, leading to lack of engagement with OPT use. HCPs continue to report pain assessment as challenging and emphasise a need for ongoing investment in training and education, which must take into consideration educational needs, and balance theory with practical application of knowledge and skills.

\section{Acknowledgements}

The authors would like to thank all research participants, participating hospices and the local collaborators within the HSC Trusts who facilitated and supported this study. 


\section{References}

391

1. Chai E, Horton JR. Managing pain in the elderly population: Pearls and pitfalls. Curr Pain Headache Rep 2010; 14:409-417. DOI: 10.1007/s11916-010-0148-0.

2. Jordan A, Lloyd-Williams M. Distress and pain in dementia. In: Hughes, J.C., Lloyd396 Williams, M., Sachs GA, editors. Supportive Care for the Person with Dementia Oxford: Oxford University Press; 2010.

p. $129-137$.

DOI: 10.1093/acprof:oso/9780199554133.001.0001.

399

400

401

402

3. American Psychiatric Association. Diagnostic and Statistical Manual of Mental Disorders.

403

404

405

4. Cervo FA, Raggi RP, Bright-Long LE, et al. Use of the certified nursing assistant OPT 5th ed. Arlington; VA: American Psychiatric Association; 2013. DOI: 10.1176/appi.books.9780890425596.

406 (CPAT) in nursing home residents with dementia. Am J Alzheimer's Dis Other Dem 2007; 22:112-119. DOI: 10.1177/1533317506298907.

407

5. Khachiyants N, Trinkle D, Son SJ, et al. Sundown syndrome in persons with dementia: An update. Psychiatr Invest 2011; 8:275-287. DOI: 10.4306/pi.2011.8.4.275.

410

6. Kaasalainen S, Coker E, Dolovich L, et al. Pain management decision making among longterm care physicians and nurses. West J Nurs Res 2007; 29:561-580. DOI: 10.1177/0193945906295522. 
415 7. Krishnamoorthy A, Anderson D. Managing challenging behaviour in older adults with 416 dementia. Prog Neurol Psychiatry 2011; 15:20-27. DOI: 10.1002/pnp.199.

417

418 8. Pieper MJC, van Dalen-Kok AH, Francke AL, et al. Interventions targeting pain or 419 behaviour in dementia: A systematic review. Ageing Res Rev 2013; 12:1042-1055. DOI: 10.1016/j.arr.2013.05.002.

421

9. Ahn H, Garvan C, Lyon D. Pain and aggression in nursing home residents with dementia: Minimum data set 3.0 analysis. Nurs Res 2015; 64:256-263. DOI: 10.1097/NNR.0000000000000099.

425

426

10. Afzal N, Buhagiar K, Flood J, et al. Quality of end-of-life care for dementia patients during 427 acute hospital admission: A retrospective study in Ireland. Gen Hosp Psychiatry 2010;

429

11. Park J, Castellanos-Brown K, Belcher J. A review of observational pain scales in nonverbal 32:141-146. DOI: 10.1016/j.genhosppsych.2009.10.003. elderly with cognitive impairments. Res Soc Work Pract 2010; 20:651-664. DOI:

12. Lints-Martindale AC, Hadjistavropoulos T, Lix LM, et al. A comparative investigation of observational OPTs for older adults with dementia. Clin J Pain 2012; 28:226-237. DOI: 10.1177/1049731508329394. 
457

458

459

460

13. Bruneau B. Barriers to the management of pain in dementia care. Nur Times 2014; 110:1215.

14. Herr K, Bjoro K, Decker S. Tools for assessment of pain in nonverbal older adults with dementia: A state-of-the-science review. J Pain Symptom Manage 2006; 31:170-192. DOI: 10.1016/j.jpainsymman.2005.07.001.

15. Lichtner V, Dowding D, Esterhuizen P, et al. Pain assessment for people with dementia: A systematic review of systematic reviews of pain assessment tools. BMC Geriatr 2014; 14:1. doi: $10.1186 / 1471-2318-14-138$.

16. Department of Health. Living well with dementia: a National Dementia Strategy. 2009. DOH.https://www.gov.uk/government/uploads/system/uploads/attachment_data/file/1682 20/dh 094051.pdf. Accessed 21 Aug 2015.

17. Department of Health, Social Services and Public Safety. Improving dementia services in Northern Ireland: a regional strategy. 2011. DHSSPS: Northern Ireland. https://www.dhsspsni.gov.uk/sites/default/files/publications/dhssps/improving-dementiaservices-2011.pdf. Accessed 21 Aug 2015.

18. World Health Organisation. Dementia: a public health priority. WHO. 2012. http://www.globalaging.org/agingwatch/Articles/Dementia $\% 20 \mathrm{a} \% 20$ public $\% 20$ health $\% 2$ 
462

463

464

465

466

467

468

469

470

471

472

473

474

475

476

477

478

479

480

481

482

483

484

485

486

19. van der Steen JT, Radbruch L, Hertogh CM, et al. White paper defining optimal palliative care in older people with dementia: A Delphi study and recommendations from the European Association for Palliative Care. Palliat Med 2014; 28:197-209. DOI: $10.1177 / 0269216313493685$.

20. Zwakhalen SMG, Hamers JPH, Abu-Saad HH, et al. Pain in elderly people with severe dementia: A systematic review of behavioural pain assessment tools. BMC Geriatr 2006; 6:3. DOI: $10.1186 / 1471-2318-6-3$.

21. Van Herk R, Van Dijk M, Baar FPM, et al. Observation scales for pain assessment in older adults with cognitive impairments or communication difficulties. Nurs Res 2007; 56:3443.

22. Brorson H, Plymoth H, Örmon K, et al. Pain relief at the end of life: Nurses' experiences regarding end-of-life pain relief in patients with dementia. Pain Manage Nurs 2014; 15:315-323. DOI: 10.1016/j.pmn.2012.10.005.

23. Regnard C, Reynolds J, Watson B, et al. Understanding distress in people with severe communication difficulties: Developing and assessing the Disability Distress Assessment Tool (DisDAT). J Intellect Disabil Res 2007; 51:277-292. DOI: 10.1111/j.13652788.2006.00875.x.

24. Van der Steen JT, Regnard C, Volicer L, et al. Detecting pain or distress in people with dementia: An appraisal of two strategies. Eur J Palliative Care 2015; 22:110-113. 
499

500

501

502

503

504

505

506

507

508

509

510

25. Ballard C, Creese B, Corbett A, et al. Atypical antipsychotics for the treatment of behavioral and psychological symptoms in dementia, with a particular focus on longer term outcomes and mortality. Expert Opin Drug Saf 2011; 10:35-43. DOI: $10.1517 / 14740338.2010 .506711$.

26. Zwakhalen SMG, Hamers JPH, Peijnenburg RHA, et al. Nursing staff knowledge and belief about pain in elderly nursing home residents with dementia. Pain Res Manage 2007; $12: 177-184$.

27. Barry HE, Parsons C, Passmore AP, et al. An exploration of nursing home managers' knowledge of and attitudes towards the management of pain in residents with dementia. Int J Geriatr Psychiatry 2012; 27:1258-1266. DOI: 10.1002/gps.3770.

28. Ghandehari OO, Hadjistavropoulos T, Williams J, et al. A controlled investigation of continuing pain education for long-term care staff. Pain Res Manage 2013; 18:11-18.

29. Pasero C, McCaffery M. No self-report means no pain-intensity rating. Am J Nurs 2005; 105(10):50-3.

30. Buffum MD, Hutt E, Chang VT, et al. Cognitive impairment and pain management: review of issues and challenges. J Rehabil Res Dev 2007; 44:315-30.

31. Braun V, Clarke V. Using thematic analysis in psychology. Qual Res Psychol 2006; 3(2):77-101. DOI: 10.1191/1478088706qp063oa. 
512

513

514

515

516

517

518

519

520

521

522

523

524

525

526

527

528

529

530

531

532

533

32. Abbey J, Piller N, De Bellis A, et al. The Abbey pain scale: a 1-minute numerical indicator for people with end stage dementia. Int $J$ Palliat Nurs 2004;10:6-14 DOI: 10.12968/ijpn.2004.10.1.12013.

33. Pieper MJ, van der Steen JT, Francke AL, et al. Effects on pain of a stepwise multidisciplinary intervention (STA OP!) that targets pain and behaviour in advanced demntia: A cluster randomized controlled trial. Palliat Med 2018; 32(3):682-692. DOI: $10.1177 / 0269216316689237$.

34. Hadjistavropoulos T, Fitzgerald TD, Marchildon GP. Practice guidelines for assessing pain in older persons with dementia residing in long-term care facilities. Physiother Can 2010; 62(2): 104-113. DOI: 10.3138/physio.62.2.104.

35. Regnard C. Pain is not the only cause of distress in dementia. BMJ 2011; 343:7821. DOI: 10.1136/bmj.d5355.

36. Kovach CR, Griffie J, Muchka S, et al. Nurses' perceptions of pain assessment and treatment in the cognitively impaired elderly. It's not a guessing game. Clin Nurse Spec $2000 ; 14: 215-220$.

37. Kappesser J, Williams AC, Prkachin KM. Testing two accounts of pain underestimation. Pain 2006; 124:109-116. DOI: 10.1016/j.pain.2006.04.003. 
535

536

537

538

539

540

541

542

543

544

545

546

547

548

549

550

551

552

553

554

555

556

557

38. McAuliffe L, Brown D, Fetherstonhaugh D. Pain and dementia: An overview of the literature. Int J Older People Nurs 2012; 7:219-226. DOI: 10.1111/j.17483743.2012.00331.x.

39. Burns M, McIlfatrick S. Palliative care in dementia: Literature review of nurses' knowledge and attitudes towards pain assessment. Int J Palliative Nurs 2015; 21:400-407. DOI: 10.12968/ijpn.2015.21.8.400.

40. Cohen-Mansfield J. Even with regular use of an observational scale to assess pain among nursing home residents with dementia, pain-relieving interventions are not frequently used. Evid - Based Nurs 2014; 17:24-25. DOI: 10.1136/eb-2012-101205.

41. McGlynn EA, Asch SM, Adams J, et al. The quality of health care delivered to adults in the United States. N Engl J Med 2003; 348:2635-2645. DOI: 10.1056/NEJMsa022615.

42. Green LA, Seifert CM. Translation of research into practice: why we can't "just do it”. J Am Board Fam Pract 2005; 18(6):541-545.

43. Pronovost PJ, Berenholtz SM, Needham DM. Translating evidence into practice: a model for large scale knowledge translation. BMJ 2008; 337:1714. DOI: 10.1136/bmj.a1714.

44. Lynn J, Baily MA, Bottrell M, et al. The ethics of using quality improvement methods in health care. Ann Intern Med 2007; 146:666-673. 
45. Westfall JM, Mold J, Fagnan L. Practice-based research - "Blue Highways" on the NIH roadmap. JAMA 2007; 297:403-406. DOI: 10.1001/jama.297.4.403.

46. Grimshaw JM, Eccles MP, Lavis JN, et al. Knowledge translation of research findings. Implement Sci 2012; 7:50. DOI: 10.1186/1748-5908-7-50.

47. Cabana MD, Rand CS, Powe NR, et al. Why don't physicians follow clinical practice guidelines? A framework for improvement. JAMA 1999; 282:1458-1465.DOI: 10.1001/jama.282.15.1458.

48. Larisch A, Oertel WH, Eggert K. Attitudes and barriers to clinical practice guidelines in general and to the guideline on Parkinson's disease. A National Survey of German neurologists in private practice. J Neurol 2009; 256:1681-1688. DOI: 10.1007/s00415-0095178-3.

49. Arora S, Kalishman S, Dion D, et al. Partnering urban academic medical centers and rural primary care clinicians to provide complex chronic disease care. Health Aff 2011;30:117684. DOI: $10.1377 /$ hlthaff.2011.0278.

50. Arora S, Kalishman S, Thornton K, et al. Expanding access to Hepatitis C Virus treatment - Extension for Community Healthcare Outcomes (ECHO) Project: disruptive innovation in specialty care. Hepatology 2010;52:1124-1133 DOI: 10.1002/hep.23802. 
582

583

584

585

586

587

588

589

590

591

592

593

594

595

596

597

598

599

600

601

602

603

51. Arora S, Thornton K, Murata G, et al. Outcomes of treatment for Hepatitis C Virus Infection by primary care providers. N Engl J Med 2011;364:2199-2207. DOI: 10.1056/NEJMoa1009370.

52. Arora S, Thornton K, Komaromy M, et al. Demonopolizing medical knowledge. Acad Med 2014;89:30-32. DOI: 10.1097/ACM.0000000000000051.

53. Burdette Mendonca K. SCAN-ECHO: an effective way to provide patient-centred care. 2012; http//:www.sanfrancisco.va.gov/features/SCAN-ECHO.asp. Accessed 17 February 2016.

54. Masi C, Hamlish T, Davis A, et al. Using an established telehealth model to train urban primary care providers on hypertension management. J Clin Hypertens 2012;14:45-50. DOI: 10.1111/j.1751-7176.2011.00559.x.

55. Scott JD, Unruh KT, Catlin MC, et al. Project ECHO: a model for complex, chronic care in the Pacific Northwest region of the United States. J Telemed Telecare 2012;18:481-484. DOI: $10.1258 /$ jtt.2012.gth113.

56. Khatri K, Haddad M, Anderson D. Project ECHO: replicating a novel model to enhance access to hepatitis $\mathrm{C}$ care in a community health center. J Health Care Poor Underserved 2013;24:850-858. DOI: 10.1353/hpu.2013.0093.

604 
605

606

607

608

609

610

611

612

613

614

615

616

617

618

619

620

621

622

623

624

625

626

627

628

57. Cahana A, Dansie EJ, Theodore BR, et al. Redesigning delivery of opioids to optimise pain management, improve outcomes and contain costs. Pain Med 2013;14:36-42. DOI: 10.1111/pme.12013.

58. Katzman J, Comerci G, Boyle JF, et al. Innovative telementoring for pain management: Project ECHO Pain. J Contin Educ Health Prof 2014;34:68-75. DOI: 10.1002/chp.21210.

59. White C, McIlfatrick S, Dunwoody L, et al. Supporting and improving community health services - a prospective evaluation of ECHO technology in community palliative care nursing teams. BMJ Pall Support Care 2015; December 1. DOI: 10.1136/bmjspcare2015-000935.

60. De Witt Jansen B, Brazil K, Passmore P, et al. Evaluation of the impact of telementoring using $\mathrm{ECHO}^{\odot}$ technology on healthcare professionals’ knowledge and self-efficacy in assessing and managing pain for people with advanced dementia nearing the end of life. BMC Health Serv Res 2018; in press. DOI: 10.1186/s12913-018-3032-y

61. Kovach CR, Logan BR, Noonan PE, et al. Effects of the serial trial intervention on discomfort and behaviour of nursing home residents with dementia. Am J Alzheimers Dis Other Demen 2006;21(8):147-155. DOI: 10.1177/1533317506288949.

62. Lee EE, Chang B, Huege S, et al. Complex clinical intersection: Palliative care in patients with dementia. Am J Ger Psychiatry 2018;26(2): 224-234. DOI:

629 
630

631

632

633

634

635

636

\section{Declaration of conflicting interests}

638 Professor Peter Passmore has received funding (educational grants) from Napp, Grünenthal 639 and Pfizer, and has spoken and/or chaired meetings for these companies. Napp, Grünenthal and 640 Pfizer had no role in the development, analysis or reporting of the present study. The other 641 authors have no conflicts of interest to declare.

642

\section{Availability of data and materials}

644 The audiotaped interviews were deleted from the digital recorder following transcription, in 645 accordance with institutional data protection protocols. Transcripts are not available because 646 this would render participants identifiable. 
1. Tell me about your experiences of assessing pain in patients with advanced dementia in their last few months, weeks, days and hours of life.

2. What are the likely causes of pain in people with advanced dementia in their last few months, weeks, days and hours of life?

3. Do different types of pain or different combinations of pain (e.g. breakthrough, chronic, acute, acute-on-chronic) impact on assessing whether a dying patient with dementia is in pain? If so, in what way?

4. How do you recognise/identify when a person with advanced dementia who is approaching the end of life is in pain? (Only ask if the participant doesn't cover this in the above questions)

5. Do you use pain tools to help with recognising and assessing pain?

\section{YES}

- Which one(s) do you use and why that/those one(s) in particular?

- How do you use this/these pain tool(s) in your clinical practice?

- Are the results of these pain tools recorded/documented and/or discussed with patients' family and other colleagues?

- Do the results of the pain assessment tool(s) influence the pain management strategies (i.e. the medications) that you use/prescribe? In what ways?

- What do you believe are the clinical outcomes of using these tools for managing pain in these patients?

$\mathrm{NO}$

- Are there any barriers that limit the use of pain assessment tools?

- What alternative measures do you find useful in helping you assess and manage pain?

- Are there any factors that would encourage you or make it easier for you to incorporate the use of pain assessment tools in your clinical practice?

6. Do you think that the assessment of pain in people with advanced dementia who are nearing the end of life could be improved? In what ways?

7. Do you think healthcare professionals require additional training/education in assessing pain in patients with advanced dementia? Who do you see delivering this type of training and how do you think it should be delivered? 
Table 2. Participant demographic profile

654

\begin{tabular}{|c|c|c|c|c|c|c|}
\hline & \multicolumn{3}{|c|}{ Physicians ( $n=23)$} & \multicolumn{3}{|c|}{ Nurses $(n=24)$} \\
\hline Age & & 42.5 & ( 28 years to 58 years) & & 36.8 & ( 25 years to 59 years) \\
\hline \multirow[t]{2}{*}{$\begin{array}{l}\text { Years of } \\
\text { experience }\end{array}$} & & 17.5 & ( 5 years to 31 years) & & 13.8 & ( 3 months to 34 years) \\
\hline & & $n$ & $\%$ & & $n$ & $\%$ \\
\hline \multirow[t]{2}{*}{ Gender } & Male & 7 & 30 & Male & 1 & 4 \\
\hline & Female & 16 & 70 & Female & 23 & 96 \\
\hline \multirow[t]{3}{*}{ Care settings } & Primary Care & 9 & 39 & Nursing home & 12 & 50 \\
\hline & Hospice & 7 & 30 & Hospice & 6 & 25 \\
\hline & Acute Care & 7 & 30 & Acute Care & 6 & 25 \\
\hline \multirow[t]{4}{*}{ Education } & None & 16 & 70 & None & 17 & 71 \\
\hline & Diploma & 2 & 9 & Diploma & 4 & 17 \\
\hline & Masters & 4 & 17 & Master's Degree & 3 & 13 \\
\hline & $\mathrm{PhD}$ & 1 & 4 & & & \\
\hline
\end{tabular}

655 


\begin{tabular}{|c|c|c|}
\hline Theme & Quote & Participant \\
\hline \multirow[t]{6}{*}{$\begin{array}{l}\text { Use of OPTs in } \\
\text { advanced dementia } \\
\text { towards the end of life }\end{array}$} & $\begin{array}{l}\text { "[Standardised pain assessments] can be really useful because if somebody's coming in in } \\
\text { the last few weeks it's for symptom control which is pain, so obviously you want to get that } \\
\text { sorted out straightaway. We'd be starting them on the pain chart and from that there we can } \\
\text { see where's this pain coming from? Is it from this area, this area, this area? 'Cause you } \\
\text { need to know is it the same area all the time? Is it different areas?" }\end{array}$ & $\begin{array}{l}\text { NURS06 Female, } \\
\text { RGN, Hospice }\end{array}$ \\
\hline & $\begin{array}{l}\text { "It allows us to work interchangeably with the palliative care team because that's what } \\
\text { they're used to so it means that we're working off the same page." }\end{array}$ & $\begin{array}{l}\text { PHYS03 Male, } \\
\text { Consultant } \\
\text { Psychiatrist, Hospital }\end{array}$ \\
\hline & $\begin{array}{l}\text { "[The Abbey Pain Scale] is the one that is in use in most of the nursing homes [here]. It's } \\
\text { not going to give you all the answers but it can certainly give you an indication, and it's } \\
\text { also a recognised tool so when you're speaking on behalf of the patient to the GP, if you're } \\
\text { able to say that you used this recognised tool, rather than going on and just saying "I feel } \\
\text { that my resident is in pain", [if] you have a recognised tool and an assessment and a score } \\
\text { to give them, then you'll very often find that you'll be listened to more." }\end{array}$ & $\begin{array}{l}\text { NURS010 Female, } \\
\text { RGN, Nursing Home }\end{array}$ \\
\hline & $\begin{array}{l}\text { "It is a useful tool for, for example neuro nurses who aren't aware of if somebody [who] } \\
\text { has dementia is sore, you know? We just take it as a given and we know what to look for in } \\
\text { terms of facial expression or changes in behaviours but if you were new to caring for people } \\
\text { with dementia, it is useful to say oh these are the things that I should be looking at." }\end{array}$ & $\begin{array}{l}\text { NURS015 Female, } \\
\text { RGN, Nursing Home }\end{array}$ \\
\hline & $\begin{array}{l}\text { "It's easy probably if you can see those tell-tale signs that the Abbey Pain Chart is asking } \\
\text { you but whenever the resident is just completely unconscious you would question it. If } \\
\text { there is another tool that we could use and compare it with, yeah why not, but I think we } \\
\text { have been using Abbey Pain Chart for quite a while and you would question does it really } \\
\text { work? You know? Is there something better out there that we could use?" }\end{array}$ & $\begin{array}{l}\text { NURS02 Female, } \\
\text { Nurse, Nursing } \\
\text { Home }\end{array}$ \\
\hline & $\begin{array}{l}\text { "Well I would sometimes use the PAINAD, you know, the PAINAD advanced dementia } \\
\text { tool, not as formally as counting it up but just using the facial expression and behaviour and } \\
\text { vocalisation measurements to assess. But I wouldn't formally put a score on it." }\end{array}$ & $\begin{array}{l}\text { PHYS04 Female, GP, } \\
\text { Primary Care }\end{array}$ \\
\hline
\end{tabular}




\begin{tabular}{|c|c|c|}
\hline \multirow[t]{6}{*}{$\begin{array}{l}\text { Barriers to the use of } \\
\text { OPTs and the } \\
\text { importance of "added } \\
\text { value" }\end{array}$} & $\begin{array}{l}\text { "We wouldn't routinely use a tool like that in our in-patient setting unless we were } \\
\text { struggling because it's kind of what we do, and we're very tuned in to it so a tool doesn't } \\
\text { add anything on top of what we already know and what we're already assessing." }\end{array}$ & $\begin{array}{l}\text { PHYS01 Female, } \\
\text { Consultant in } \\
\text { Palliative Medicine, } \\
\text { Hospice }\end{array}$ \\
\hline & $\begin{array}{l}\text { "I'm not using any standardised pain assessments for people with dementia. It's not the way } \\
\text { I've been trained or taught in our medical school and in clinical practice. I take a history } \\
\text { find out what they've been like before and then find out what they're like now and then do } \\
\text { a medical assessment: do they have a temperature, any evidence of infection, chest } \\
\text { infection, kidney infections, what are they like when they're being moved by the nursing } \\
\text { staff, whenever they're moved do they appear to be in pain? I do a medical assessment and } \\
\text { then do a physical examination, you know, chest, heart, abdomen make sure they haven't } \\
\text { got retention of urine, and also move their arms and their legs see if there is anything } \\
\text { obvious there." }\end{array}$ & $\begin{array}{l}\text { PHYS021 Male, GP, } \\
\text { Primary Care }\end{array}$ \\
\hline & $\begin{array}{l}\text { "I would have noticed that staff were perhaps guessing that the score was going to be the } \\
\text { same and they weren't going back and actually looking at the resident and assessing them." }\end{array}$ & $\begin{array}{l}\text { NURS010 Female, } \\
\text { Nurse, Nursing } \\
\text { Home }\end{array}$ \\
\hline & $\begin{array}{l}\text { "I think that when one gets into such a routine that you use the skills which you've } \\
\text { acquired, you don't necessarily move to just start using a new tool." }\end{array}$ & $\begin{array}{l}\text { PHYS05 Male, } \\
\text { Consultant } \\
\text { Psychiatrist, Hospital }\end{array}$ \\
\hline & $\begin{array}{l}\text { "They're coming in with the Abbey Pain Scale, they're teaching how to administer it in a } \\
\text { very quick manner but they're not actually showing why it needs to be done and showing } \\
\text { the uniqueness of end stage dementia and the unique challenges that that presents." }\end{array}$ & $\begin{array}{l}\text { NURS010 Female } \\
\text { Nurse, Nursing } \\
\text { Home }\end{array}$ \\
\hline & $\begin{array}{l}\text { "The issue with policies is that there are so many different problems and there are so many } \\
\text { assessment tools now I think that the wards are kind of bombarded with that. I suppose it's } \\
\text { just making sure that we're not adding to the paperwork burden too significantly and that } \\
\text { the staff are aware of how to use those tools to work out if they patients seem sore and } \\
\text { emphasising the best practice approach to symptom assessment and management." }\end{array}$ & $\begin{array}{l}\text { PHYS015 Male } \\
\text { Consultant Palliative } \\
\text { Medicine Hospice }\end{array}$ \\
\hline $\begin{array}{l}\text { Perspectives on practice } \\
\text { development and } \\
\text { training in pain }\end{array}$ & $\begin{array}{l}\text { "I think there should be a rolling programme within the Trust, I think it should be part of } \\
\text { our mandatory training, and I think it should be for all levels of staff. I think it is a major, } \\
\text { major gap within the Trust. I think it's a major gap within the NHS as a whole. It is trying }\end{array}$ & $\begin{array}{l}\text { NURS022 Female } \\
\text { Nurse Hospital }\end{array}$ \\
\hline
\end{tabular}




\begin{tabular}{|c|c|c|}
\hline \multirow[t]{3}{*}{$\begin{array}{l}\text { assessment in advanced } \\
\text { dementia in end of life } \\
\text { care }\end{array}$} & $\begin{array}{l}\text { to get that balance of ensuring the fact that they have dementia doesn't take away from the } \\
\text { fact that they still need clinically treated in exactly the same way as a person who is compos } \\
\text { mentis and doesn't have any cognitive issues. I think it [pain assessment] should be part of } \\
\text { the induction, I think it should be mandatory training." }\end{array}$ & \\
\hline & $\begin{array}{l}\text { "You could have a case report like "Mr X has such and such" and then group work to try } \\
\text { and figure out what could be the possible causes, what to look out for, how to use the tool } \\
\text { in that case and things like that." }\end{array}$ & $\begin{array}{l}\text { PHYS06 Female } \\
\text { Psychiatrist Hospital }\end{array}$ \\
\hline & $\begin{array}{l}\text { "I think a key thing would be to assess does it actually change their practice or influence } \\
\text { their practice because sometimes training is done but the benefits can be lost if they're not } \\
\text { implemented by the person and if there's not a culture of change. There has to be a culture, } \\
\text { staff have to be working in an environment where there's a culture of improvement and } \\
\text { where there is attention given to that particular area." }\end{array}$ & $\begin{array}{l}\text { PHY015 Male, } \\
\text { Consultant Palliative } \\
\text { Medicine, Hospice }\end{array}$ \\
\hline
\end{tabular}

